\title{
Influence of substrate topography on cathodic delamination of anticorrosive coatings
}

\author{
Sørensen, Per Aggerholm; Kiil, Søren; Dam-Johansen, Kim; Erik Weinell, Claus
}

Published in:

Progress in Organic Coatings

Link to article, DOI:

10.1016/j.porgcoat.2008.08.027

Publication date:

2009

Link back to DTU Orbit

Citation (APA):

Sørensen, P. A., Kiil, S., Dam-Johansen, K., \& Erik Weinell, C. (2009). Influence of substrate topography on cathodic delamination of anticorrosive coatings. Progress in Organic Coatings, 64(2-3), 142-149.

https://doi.org/10.1016/j.porgcoat.2008.08.027

\section{General rights}

Copyright and moral rights for the publications made accessible in the public portal are retained by the authors and/or other copyright owners and it is a condition of accessing publications that users recognise and abide by the legal requirements associated with these rights.

- Users may download and print one copy of any publication from the public portal for the purpose of private study or research.

- You may not further distribute the material or use it for any profit-making activity or commercial gain

- You may freely distribute the URL identifying the publication in the public portal

If you believe that this document breaches copyright please contact us providing details, and we will remove access to the work immediately and investigate your claim 


\title{
Influence of Substrate Topography on Cathodic Delamination of Anticorrosive Coatings
}

\author{
P. A. Sørensen ${ }^{a}$, S. Kiil ${ }^{a^{*}}$, K. Dam-Johansen ${ }^{a}$, C. E. Weinell ${ }^{\text {b }}$ \\ ${ }^{a}$ Department of Chemical and Biochemical Engineering, Technical University of Denmark, Building 229, \\ DK-2800 Kgs. Lyngby, Denmark \\ ${ }^{b}$ Hempel A/S, Lundtoftevej 150 DK-2800 Kgs. Lyngby, Denmark \\ * Corresponding author. Tel.: +45 45252827; fax: +45 45882258. E-mail address: sk@kt.dtu.dk
}

\begin{abstract}
The cathodic delamination of a commercial $\mathrm{TiO}_{2}$ pigmented epoxy coating on abrasive cleaned cold rolled steel has been investigated. The rate of delamination was found to depend on interfacial transport from the artificial defect to the delamination front and thereby the substrate topography, whereas the coating thickness had little influence. The presence of a significant potential gradient between the anode and the cathode and the dependency of the delamination rate on the tortuosity of the steel surface suggests that cathodic delamination is controlled by migration of cations from the defect to the delamination front. This means that abrasive blasting, to some extent, can be applied to control and minimize the observed rate of cathodic delamination. The lifetime of the species causing disbondment suggested that sodium hydroxide or potassium hydroxide and not peroxide species or radicals are the causative agents at free corrosion potential (i.e. without impressed current).
\end{abstract}

\section{Introduction}

Organic barrier coatings are frequently applied to prevent corrosion of steel structures immersed in sea or fresh water by preventing aggressive species from getting into direct contact with the steel. To protect the steel from corrosion, the coating must maintain adequate adhesion to the steel during environmental exposure [1]. Inadequate adhesion will promote failure of the coating system and subsequent exposure of the bare steel to the aggressive environment, causing corrosion. For this reason mechanisms of adhesion [2-5] and de-adhesion have been subject to numerous studies [6-12].

Intact and properly applied anticorrosive coating systems may have lifetimes of up to 20 years. However, if the coatings are inadequately applied or get physically damaged during service, the lifetime of the coating system may be much less. If a part of the anticorrosive coating is damaged e.g. by impacts, scratches or wear, the surrounding environment will be in direct contact with the bare steel, and in the presence of water and ions electrochemical reactions will take place at the electrolyte-coating-steel interface [6, 10, 12-18]. The anodic attack, eq. 1, on the exposed steel initiates when an electrochemical cell in which oxygen is reduced at cathodic sites beneath the coating on un-corroded steel develops. The reduction of oxygen to hydroxyl ions, eq. 2, on a steel surface at free corrosion potential also involves water and electrons generated by the anodic reaction [19].

$F e(s) \rightarrow F e^{2+}(a q)+2 e^{-}$ 
$4 e^{-}+\mathrm{O}_{2}(a q)+2 \mathrm{H}_{2} \mathrm{O}(l) \rightarrow 4 O H^{-}(a q)$

The cathodic reaction may produce reaction products underneath the coating which, according to Pourbaix [20], tend to inhibit anodic attack in these areas but adversely affect the adhesion between the anticorrosive coating and the steel. This effect has been termed cathodic delamination because similar effects can be obtained if the steel is cathodically polarized by means of an external potential [21].

The detailed mechanism of cathodic delamination originating from a well defined defect in coating system is not completely understood and several important aspects remain in dispute [8]. Therefore, several attempts to understand the basic corrosion reactions occurring at the coating-steel interface have been made. It is generally stated that the delamination of organic coatings is the result of an alkaline environment caused by the cathodic reduction of oxygen to hydroxyl ions $[6,8]$.

Various electrochemical techniques have been applied to show that defect-free organic coatings provide sufficient protection of the coated metal against corrosion although typical anticorrosive coatings are sufficiently permeable to water and oxygen so that the transport of these molecules can not determine the rate of cathodic delamination in naturally encountered environments [22-25].

In order to balance the charge of the negatively charged hydroxyl ions (e.g. preserve local charge neutrality), positively charged ions must be transported from the bulk solution to the cathodic sites. The high $\mathrm{pH}$ observed at the cathodic sites underneath the delaminated coating [16] is a strong indication for the presence of alkali metal ions at the coating-steel interface because the solubility of various hydroxides of divalent ions is low. The presence of alkali metal ions has been confirmed by local Auger spectroscopy, which has shown that underneath delaminated coatings exposed to sodium chloride significant amounts of sodium ions are present on the steel surface whereas chloride ions are excluded from the interface [25].

In the case of a defect in the coating, cations can be transported to the cathodic sites by a number of pathways e.g. along the coating-steel interface, through the intact coating and through the coating in the delaminated region as illustrated in Figure 1 [26]. If the cations are transported through the coating, they may upon entering the coating-steel interface be transported along the coating-steel interface because the transport of ions along the coating-steel interface has been found to be much faster than that through the coating [27]. In general, the transport of cations along the coating-steel interface from the defect to the delamination front is considered the rate determining step in cathodic delamination $[6,8]$. However, transport perpendicular to the coating has also been suggested as the rate determining step [26]. Other studies show that cations might be transported through the coating when the coated steel is under cathodic polarisation [28-30]. 


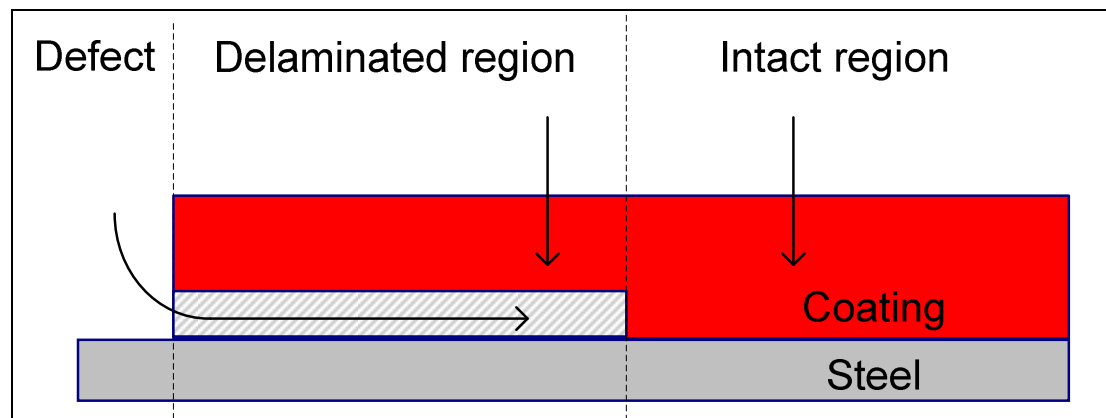

Figure 1: Possible routes of cations required for local charge neutralization of hydroxyl ions in the coating-steel interface.

This paper investigates the mechanism of cathodic delamination of a simple commercial titanium dioxide $\left(\mathrm{TiO}_{2}\right)$ pigmented epoxy coating on abrasive blasted cold rolled steel. The focus of the study is to determine the route of the cations from the bulk solution to the delamination front and quantify some of the parameters affecting the rate of delamination.

\section{Experimental}

\section{Strategy of investigations}

In order to determine the main route of the cations required for charge neutralization of the hydroxyl ions and hereby revealing part of the detailed mechanism of cathodic delamination, the effect of blocking the artificial defect, coating thickness and substrate topography on the rate of cathodic delamination has been investigated. Table 1 illustrates the type of transport, which is affected by a specific type of experiment.

\begin{tabular}{|l|c|c|c|}
\hline Type of transport & Blockage of defect & Coating thickness & Substrate topography \\
\hline Interfacial & $\mathrm{X}$ & - & $\mathrm{X}$ \\
\hline Perpendicular & - & $\mathrm{X}$ & - \\
\hline
\end{tabular}

Table 1: Type of transport affected by specific type of experiment. "Interfacial" refers to transport along the coating-steel interface while "perpendicular" refers to transport perpendicular to the coating (i.e. through the coating).

\section{Preparation of specimens}

Substrate test specimens consisting of cold rolled low-alloy carbon steel (maximum $0.18 \%$ carbon) were cut from steel plates. No oils were applied during rolling or cutting of the steel. Final dimension of the specimens were 150x70x3 mm. Prior to surface preparation, the specimens were degreased with an alkaline degreasing agent, Hempel Light Clean , thoroughly rinsed with distilled water, wiped with dust free paper and allowed to dry completely.

\section{Surface preparation}

Two different types of surface preparation were applied, respectively abrasive blasting and abrasive polishing. Two types of chilled iron-grit were applied for abrasive blasting to investigate the effect of grain size on the surface topography (i.e. profile height and peak density). In theory, small size grit particles should give a greater number of peaks 
than large size grit, but the velocity of the grains (working pressure) must be increased if a similar profile height should be achieved [31]. The type of iron-grit and applied working pressure during abrasive blasting of the steel specimens is given in Table 2 , while Table 3 gives the size distribution of the two types of chilled iron-grit. Microscopic views of the iron-grits are given in Figure 2 and 3.

\begin{tabular}{|l|c|c|}
\hline Substrate & Grit type & Pressure [bar] \\
\hline ID-1 & $-^{\mathrm{a}}$ & - \\
\hline ID-2 & G-12 & 3 \\
\hline ID-3 & G-07 & 3 \\
\hline ID-4 & G-07 & 7 \\
\hline ID-5 & G-12 & 7 \\
\hline ID-6 & G-12 & 6 \\
\hline ID-7 & G-12 & 6 \\
\hline ID-8 & G-12 & 6 \\
\hline ID-9 & G-07 & 2 \\
\hline
\end{tabular}

Table 2: Surface preparation parameters. G-07 and G-12 refers to the size of the applied iron-grit. ${ }^{\text {a }}$ Abrasive polished with $3 \mathrm{M}$ abrasive paper with grain sizes ranging from P80 to P4000. ${ }^{\mathrm{b}}$ Abrasive polished with 3M abrasive paper with grain sizes ranging from P120 to P240.

\begin{tabular}{|l|r|r|}
\hline \multicolumn{1}{|c|}{ Grain size } & \multicolumn{1}{c|}{ G-07 } & \multicolumn{1}{c|}{ G-12 } \\
\hline$<63 \mu \mathrm{m}$ & $0.16 \%$ & $0.10 \%$ \\
\hline $63-90 \mu \mathrm{m}$ & $0.06 \%$ & $0.02 \%$ \\
\hline $90-150 \mu \mathrm{m}$ & $0.36 \%$ & $0.06 \%$ \\
\hline $150-250 \mu \mathrm{m}$ & $21.27 \%$ & $1.56 \%$ \\
\hline $250-300 \mu \mathrm{m}$ & $33.81 \%$ & $4.89 \%$ \\
\hline $300-355 \mu \mathrm{m}$ & $27.83 \%$ & $10.74 \%$ \\
\hline $355-425 \mu \mathrm{m}$ & $15.87 \%$ & $16.92 \%$ \\
\hline $425-500 \mu \mathrm{m}$ & $0.33 \%$ & $19.96 \%$ \\
\hline $500-741 \mu \mathrm{m}$ & $0.31 \%$ & $48.46 \%$ \\
\hline $741-1000 \mu \mathrm{m}$ & $0.01 \%$ & $0.43 \%$ \\
\hline
\end{tabular}

Table 3: Size distribution of grains in the iron-grit used for abrasive blasting of steel specimens. G-07 and $\mathbf{G - 1 2}$ refers to the size of the applied grit [32].

In order to achieve the most effective abrasive blasting and minimize residual grits on the surface, the blasting angle was kept between 55 and 70 degrees [33]. Abrasive polished specimens were prepared by mechanical grinding of the steel surface with $3 \mathrm{M}$ abrasive paper. After abrasive cleaning of the surface, the topography of the steel specimens was analyzed using a Talysurf PGI 1240 Aspheric Measuring System from Taylor-Hobson with a resolution of $0.8 \mathrm{~nm}$. The height of the surface profile was recorded for every $2 \mu \mathrm{m}$ along the profilemetry trace. 


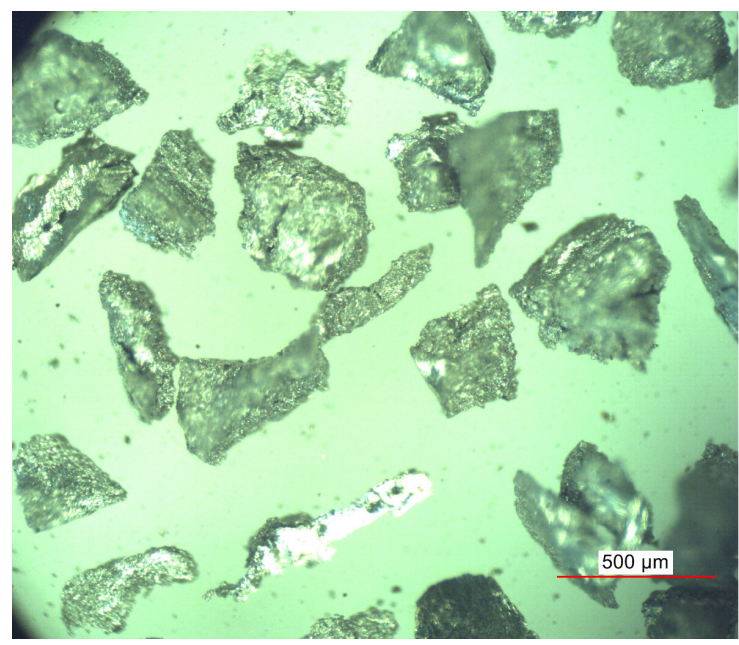

Figure 2: Microscopic view of G-07 iron-grit.

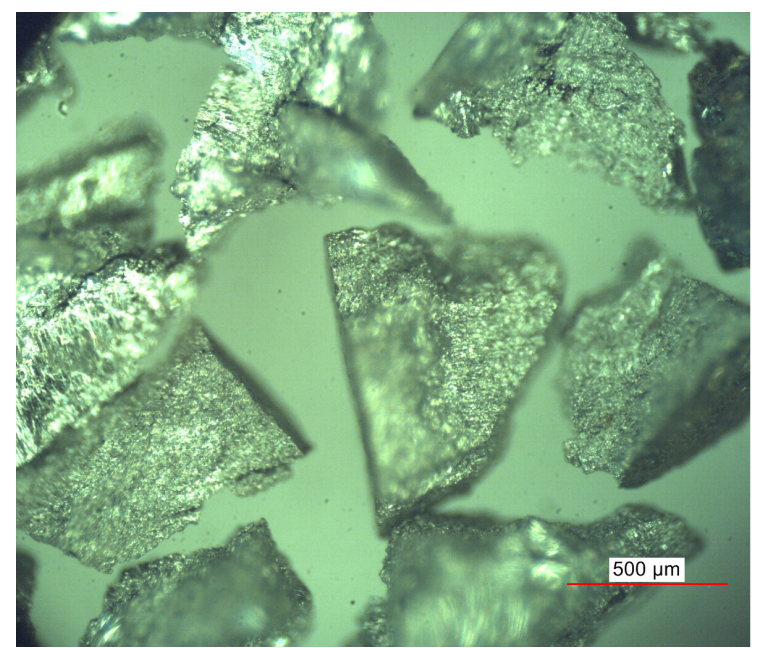

Figure 3: Microscopic view of G-12 iron-grit.

\section{Coating application}

Prior to application of a commercial $\mathrm{TiO}_{2}$ pigmented epoxy coating, the steel specimens were blown with compressed air at a pressure of 9 bar for removal of dust and residuals from the surface preparation. The coating was applied by airless spraying at a pressure of 100 to 110 bar with a standard 0.019 ' $60^{\circ}$ nozzle. In order to achieve the desired coating thickness, two coats were applied. The first coat was allowed to cure 1 day before the second coat was applied. To avoid undesired processes, which might interfere with the measurements, the backside and the edges of the substrate were sealed with the same type of coating. The dry coating thickness was measured using a magnetic coating thickness gauge and the coatings were allowed to cure for at least three weeks prior to exposure.

\section{Exposure and evaluation}

A $50 \mathrm{~mm}$ vertical scribe with a width of $2 \mathrm{~mm}$ was centred on the front of each specimen using a special tailor-made pneumatic tool that removes the coating down to the steel surface. Subsequently, the specimens were exposed to an aerated $0.5 \mathrm{M}$ solution of either sodium chloride or potassium chloride at free corrosion potential at an angle of 70 to $75^{\circ}$. A thermostat was used to keep the temperature of the electrolyte solution constant. The disbonded area was determined by removal of the coating in the delaminated regions with a sharp knife. The borders between the disbonded and intact areas were distinct. The distance of the disbonded area was determined using internal image calibrations and digital imaging software. Each measuring point constitutes the average of three specimens on which 9 distances have been measured (ISO 15711 [34]) as illustrated in Figure 5. 


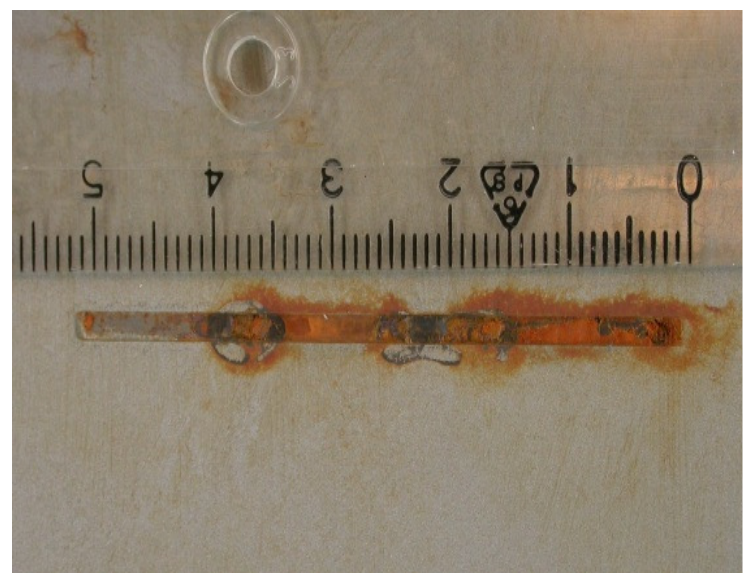

Figure 4: Top view of coating prior to removal of the coating in the delaminated regions. The damaged area may appear to be confined to the artificial defect.

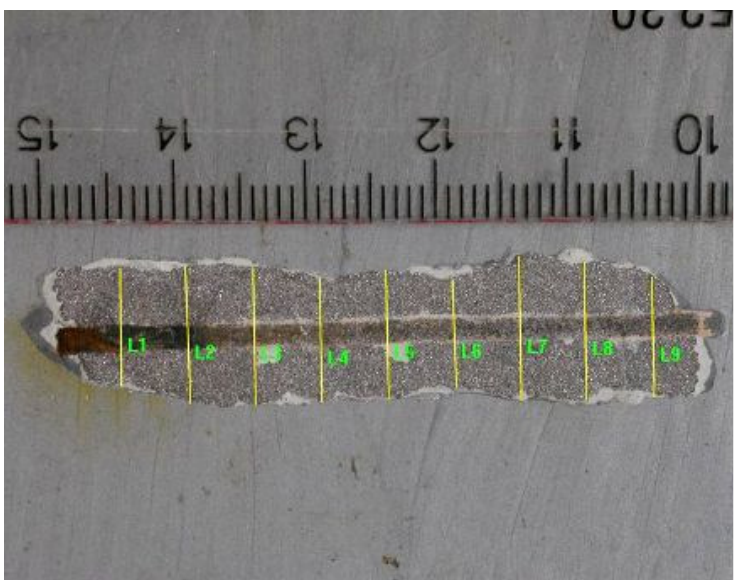

Figure 5: Evaluation of delaminated distance after removal as the coating in the delaminated regions. The true extent of degradation of the coating is not visible before the coating is removed.

\section{Results and discussion}

In this section, the results of the topographic analysis and delamination experiments are presented. Underneath the coating in delaminated regions, a $\mathrm{pH}$ around 13 and blank uncorroded steel was found. For both polished and grit-blasted surfaces, the locus of failure were at the coating-steel interface. The complete segregation of coating and the thin layer of iron oxide suggest that the mode of failure is interfacial fracture. The delamination rate on grit or abrasive cleaned substrates which was not thoroughly with ethanol and compressed air cleaned prior to application of the coating was significantly greater than the delamination rate on substrates which were thoroughly cleaned. Microscopic analysis of the delaminated coatings on clean and non-cleaned steel showed large amounts of dust and residual grit on non-cleaned substrates compared to the cleaned substrates. The presence of dust and residual grit results in regions with no or little adhesion between the coating and the steel, which will promote the risk of coating failure. This means that through cleaning of the substrate prior the application of the coating is essential for the ability of the coating to withstand cathodic delamination and protect the substrate.

\section{Topographic characteristics of the uncoated steel}

The most immediate effects of abrasive cleaning are seen as changes in the surface topography. The topography of a surface is commonly described by traditional roughness parameters such as the arithmetic roughness average, $R_{a}$, the arithmetic mean of maximum peak-to-valley height of five adjoining single sampling lengths, $R_{z}$, and the peak count, $\mathrm{P}_{\mathrm{c}}$, which is the number of peaks per linear centimetre recorded as a stylus instrument moves across a fixed length of the surface [35]. A detailed description of roughness parameters as measured by stylus instruments is given in ISO 4287 [36]. However, these commonly applied roughness parameters depend on a limited number of measurements and may not provide a proper measure for the topography of a surface when measuring distances [37]. Therefore, the tortuosity, $\tau$, of the coating-steel interface has been included in Table 4. 


\begin{tabular}{|l|c|c|c|c|}
\hline Substrate & $\mathbf{R}_{\mathbf{a}}[\boldsymbol{\mu m}]$ & $\mathbf{R}_{\mathbf{z}}[\boldsymbol{\mu m}]$ & $\mathbf{P}_{\mathbf{c}}[\mathbf{p e a k s} / \mathbf{c m}]$ & $\boldsymbol{\tau}$ \\
\hline ID-1 & $0.18 \pm 0.08$ & $0.7 \pm 0.1$ & $3 \pm 1$ & 1.017 \\
\hline ID-2 & $5.6 \pm 0.2$ & $52.6 \pm 1.7$ & $75 \pm 5$ & 1.157 \\
\hline ID-3 & $7.0 \pm 0.4$ & $41.6 \pm 1.0$ & $80 \pm 6$ & 1.183 \\
\hline ID-4 & $11.1 \pm 0.7$ & $75.5 \pm 2.0$ & $58 \pm 4$ & 1.141 \\
\hline ID-5 & $13.0 \pm 0.8$ & $84.7 \pm 2.3$ & $53 \pm 5$ & 1.120 \\
\hline ID-6 & $5.9 \pm 0.4$ & $75.6 \pm 2.7$ & $53 \pm 5$ & 1.145 \\
\hline ID-7 & $8.1 \pm 0.4$ & $48.9 \pm 4.9$ & $52 \pm 2$ & 1.121 \\
\hline ID-8 & $9.2 \pm 0.8$ & $54.7 \pm 3.2$ & $57 \pm 2$ & 1.116 \\
\hline ID-9 & $11.9 \pm 0.7$ & $40.1 \pm 1.8$ & $84 \pm 7$ & 1.078 \\
\hline
\end{tabular}

Table 4: Topographic characteristics of uncoated steel specimens.

In accordance with Watts [14], the tortuosity of the coating-steel interface is defined as the ratio between the interface diffusion length (actual length) of the surface profile, L, and the apparent length profile, $\mathrm{L}_{0}$, which is assumed to be identical with the evaluation length.

$$
\tau=\frac{L}{L_{0}}
$$

\section{Height}

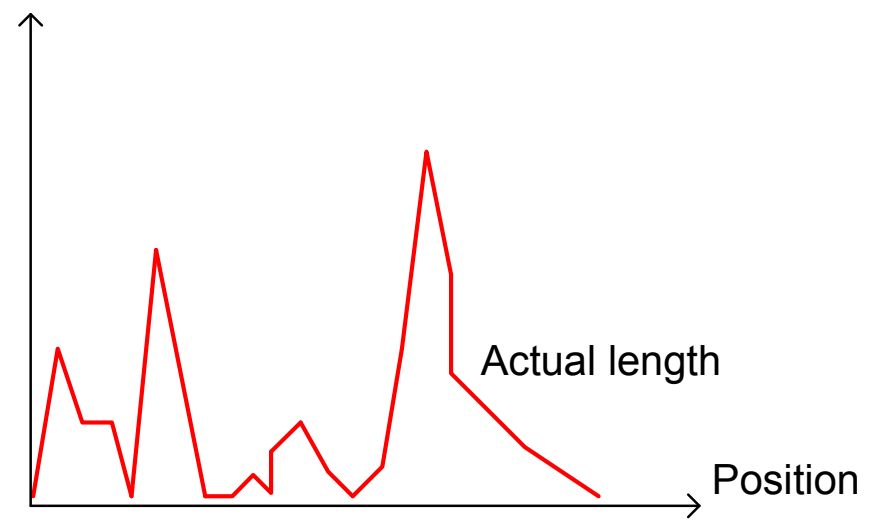

$$
\mathrm{A} \longleftrightarrow \text { Apparent length } \mathrm{B}
$$

Figure 6: The actual length of the profile is the actual measured length of the surface profile within the evaluation length (apparent length), which is the shortest way between $A$ and $B$.

The actual length of the surface profile is estimated by triangular approximation between the recorded heights of the surface profile, in accordance with ISO 4287.

$$
L=\sum_{n=1}^{N} \sqrt{\left(\frac{L_{r}}{N}\right)^{2}+\left(r_{i+1}-r_{i}\right)^{2}}
$$

where $L_{r}$ is the evaluation length, $N$ the number of measurements along the profilemetry trace and $r_{i}$ the recorded heights of the surface profile at $2 \mu \mathrm{m}$ intervals. 
As given in Table 5, the roughness grade of the prepared specimens covers the range fine to medium, which satisfy the majority of the requirements for surface roughness by the coating industry [38]. Furthermore, the topographic analysis confirms that finer grit particles produce surfaces with lower profile height and higher peak density (see Table 6). From the topographic analysis, it is obvious that the tortuosity of the coating-steel interface is affected by both profile height and peak count. This means that a coatingsteel interface with a high peak density and a fine roughness can have a greater tortuosity than a coating-steel interface with a high low peak density and a high roughness. It should be noticed that the difference in the measured tortuosity is rather small despite both speed and grain size was varied. It may be possible to increase the tortuosity further by using even finer grit particles while maintaining the roughness grade. However, this requires that the speed of the particles must be increased significantly.

\begin{tabular}{|l|r|}
\hline Roughness grade & \multicolumn{1}{|c|}{$\mathbf{R}_{\mathbf{z}}[\boldsymbol{\mu m}]$} \\
\hline Fine & $25-60$ \\
\hline Medium & $60-100$ \\
\hline Coarse & $100-150$ \\
\hline
\end{tabular}

Table 5: Roughness definitions of grit blasted steel according to ISO 8503 [39].

\begin{tabular}{|l|r|}
\hline Peak density & $\mathbf{P}_{\mathbf{c}}$ [peaks/cm] \\
\hline Low & $<40$ \\
\hline Medium & $40-70$ \\
\hline High & $70>$ \\
\hline
\end{tabular}

Table 6: Classification of peak density based on peak count, $\mathbf{P}_{\mathrm{c}}$.

\section{Route of cations}

The typical behaviour of cathodic delamination, i.e. the delaminated distance versus square root time is shown in Figure 7. In agreement with several other studies $[6,11,40$, 41], the progress of the delamination front is clearly proportional with the square root of exposure time as a correlation coefficient greater than 0.99 is found. The observation that the progress of the delamination front is proportional with the square root of time suggest that interfacial diffusion along the coating-steel interface is likely to be the ratedetermining step of the process of cathodic delamination because the mean diffusion length, $\bar{x}$, for a diffusion time, $t$, for linear isotropic and semi-infinite diffusion is given by [11]

$$
\bar{x}=2 \cdot \sqrt{\mathrm{D} \cdot \mathrm{t}}
$$

As shown in Figure 7, interfacial diffusion of cations may very well be the ratedetermining step in cathodic delamination because of the observed inhibition of the delamination when the artificial defect was sealed with a molten mixture of bee wax and natural gum rosin after four weeks exposure. This procedure represses the transport of cations along the coating-steel interface from the defect to the delamination front without affecting the transport of cations perpendicular to the coating (i.e. through the intact or delaminated regions in the coating). Hence it is clear that the main route of the cations 
required for charge neutralization of the hydroxyl ions is along the coating-steel interface and not perpendicular to the coating system.

When plotting the delamination behaviour and extrapolating the curve to intercept with the abscissa, delamination is usually found to initiate somewhat later than the start of the experiment. This time delay, which is about 165 hours, is usually considered an incubation period in which reactants penetrate the coating or activate the defect [6].

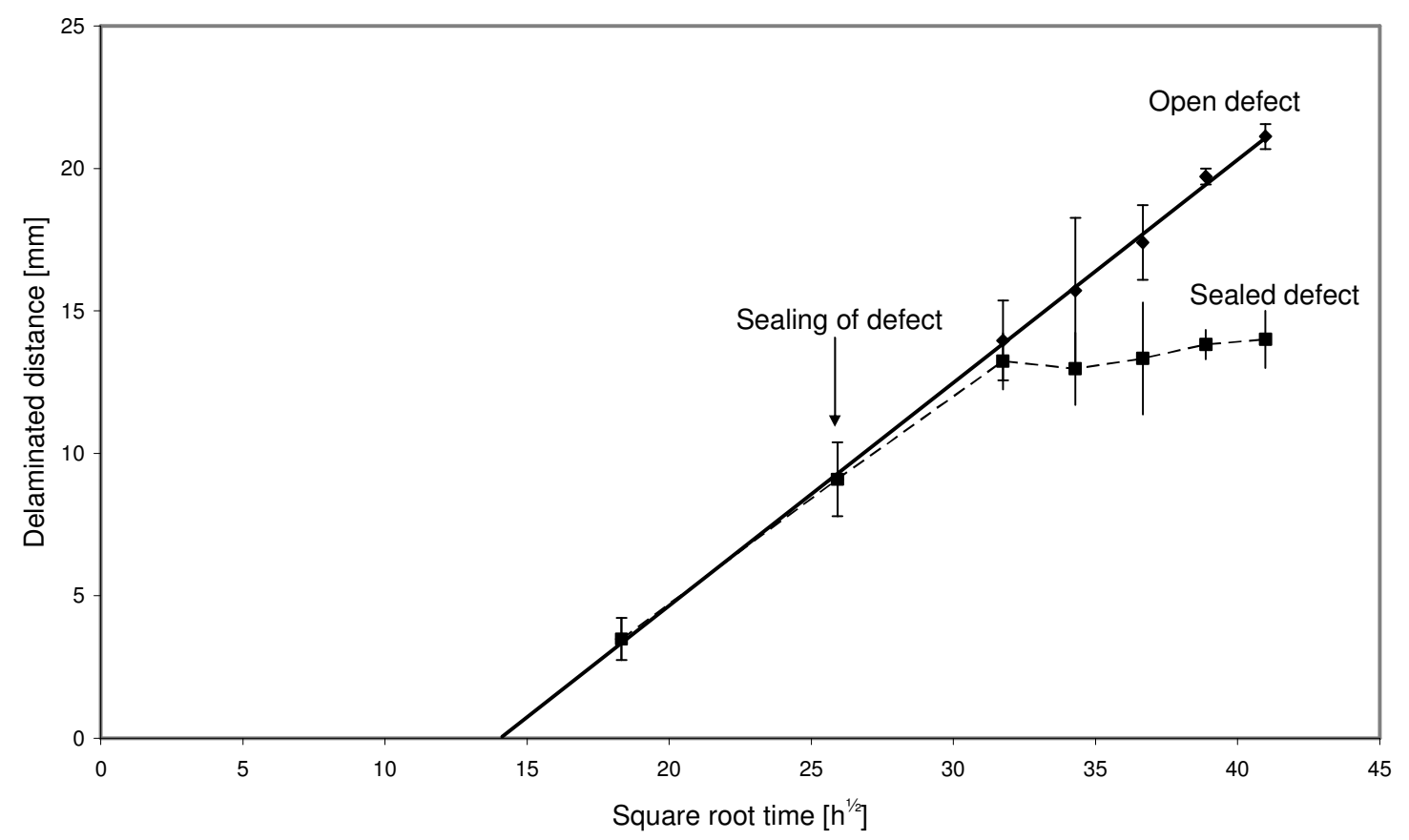

Figure 7: Delamination behaviour for an inert pigmented epoxy coating in aerated $0.5 \mathrm{M} \mathrm{NaCl}$ solution at $25^{\circ} \mathrm{C}$ with an open defect and a defect, which was sealed with a molten mixture of bee wax and natural gum rosin after 4 weeks of exposure at free corrosion potential. The vertical error bars illustrate the experimental uncertainty.

Although the main route of the cations is along the coating-steel interface, the inverse proportionality between the delaminated distance and the coating thickness illustrated in Figure 8 proves that ionic transport perpendicular to the coating can affect the rate of cathodic delamination significantly. Similar results have been obtained by other authors $[40,42]$ for coating under cathodic polarization. In contrast to other published results this particular study included the behaviour of the coating for various exposure times. The experimental results show that the range of inverse proportionality between the delaminated distance and coating thickness is continuously increased as the time of exposure progresses. This phenomenon is probably caused by the continuous penetration of cations through thicker and thicker coatings because interfacial phenomena such as wetting and adhesion between coating and steel in theory should not be affected by the thickness of the coating. Hence, the range of inverse proportionality between the coating thickness and the delaminated distance after 12 weeks is $115-179 \mu \mathrm{m}$, whereas it after 18 weeks of exposure has increased to $115-256 \mu \mathrm{m}$. The slopes of the best fit lines in the regions with inverse proportionality between the coating thickness and the delaminated 
distance were constant. This is probably caused by the transport of cations through the coating at steady state conditions because coatings behave as semi-permeable membranes [43-45]. This means that the flux through the coating is inversely proportional to the thickness of the coating.

The experimental results do not show whether the transport of cations perpendicular to the coating occur by penetration through the intact coating or through the coating in the delaminated regions. The resistivity of an intact coating is normally too high to allow significant transport of cations through the film. However, the resistivity in delaminated regions may be several orders of magnitude less than the resistivity of an attached coating [46]. The transport through the delaminated regions may be more pronounced if the coating is degraded by hydroxyl ions because the resistivity of the coating is lowered [47]. Hence, the route of the cations transported perpendicular to the coating will depend on the specific coating system.

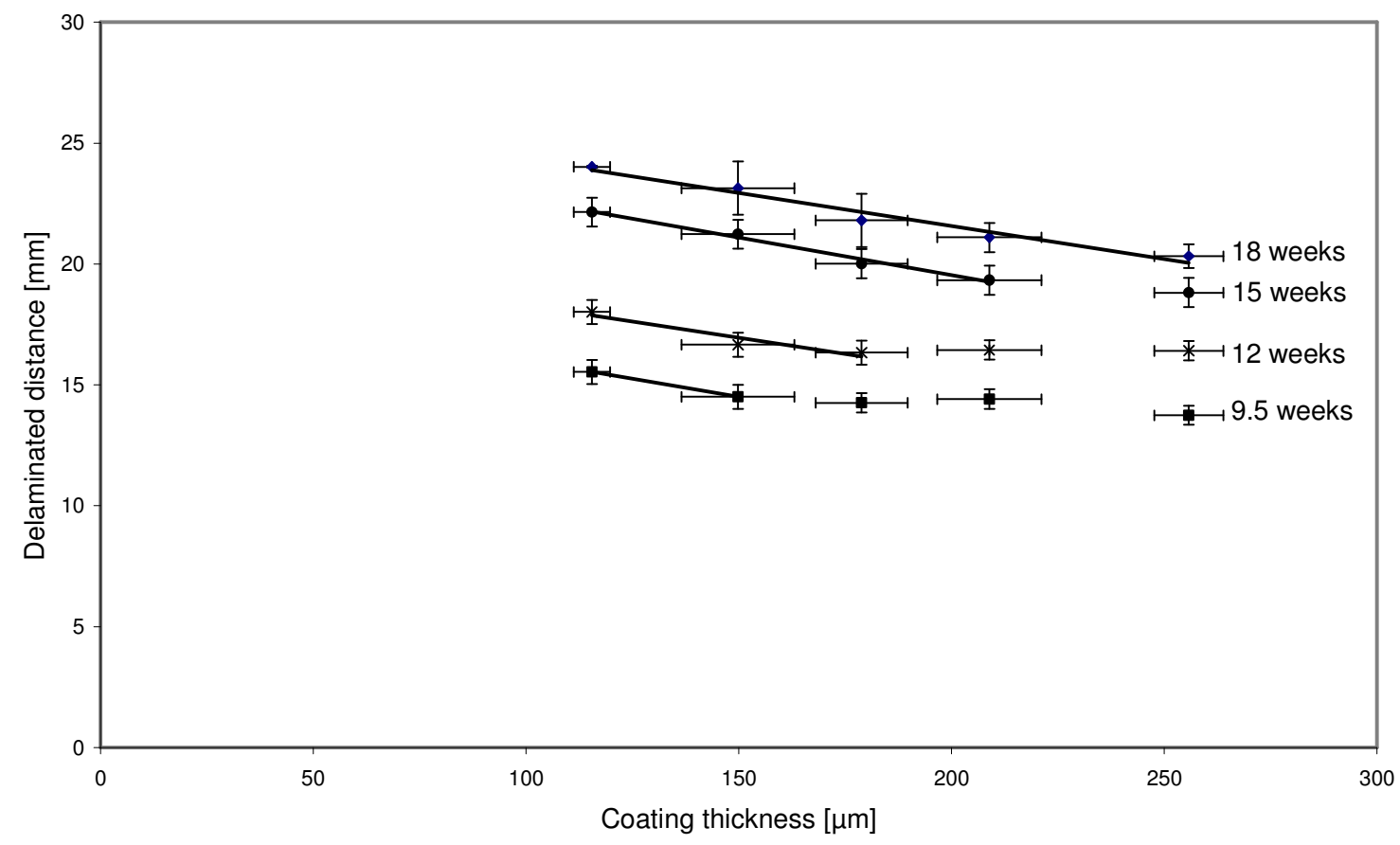

Figure 8: Distance of delamination versus coating thickness for an inert pigmented epoxy coating immersed in aerated $0.5 \mathrm{M} \mathrm{NaCl}$ at $25^{\circ} \mathrm{C}$ at free corrosion potential. The full lines show the region of inverse proportionality between the delaminated distance and coating thickness. The vertical and horizontal error bars illustrate the experimental uncertainty and the uncertainty in the coating thickness.

\section{The role of hydroxyl ions}

The processes of corrosion and cathodic delamination are highly associated with the oxidation of the metal at anodic sites coupled to the reduction of oxygen at cathodic sites. Hence, it is not surprisingly, that the reduction of oxygen plays a central role in the cathodic delamination process. 
The electrochemical reduction of oxygen dissolved in water in the presence of a steel surface at free corrosion potential can occur by two different pathways as given in Figure 9 [19]. The first option is a direct four-electron reduction of oxygen to water without intermediate formation of peroxides. The second option is a two-electron reduction of oxygen to peroxide, which can be either a final product or be further reduced to water, i.e. the serial four electron pathway. When impressed current cathodic protection is applied, the complexity of the electrochemical processes involved in the reduction of oxygen reduction increases and several other intermediates namely, superoxide and hydroxy radicals may also be formed [48-50].

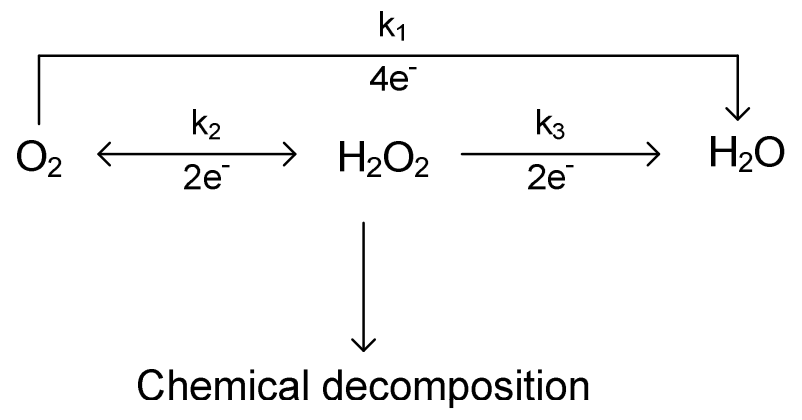

Figure 9: Pathways for electrochemical reduction of oxygen.

As shown in Figure 10, the rate of delamination of organic coatings in sodium chloride is significantly faster than the delamination in sodium hydroxide. Similar results have been obtained by other authors [10], who suggest that the presence of peroxide species may be even more detrimental to the coating-steel interface than hydroxyl ions and contribute significantly to the delamination of organic coatings. However, the observed difference may also simply illustrate the strong coupling between the corrosion processes and cathodic delamination because no corrosion occurs at specimens exposed to a $1 \mathrm{M}$ sodium hydroxide solution due to passivity of the steel surface [20]. The absence of corrosion processes on the passivated steel provides dissimilar conditions for ionic transport in the coating-steel interface compared to coated steel which corrodes. In the absence of a cathodic reaction and corrosion processes, there will be no potential gradient between the defect on the delamination front (i.e. $\frac{d \phi}{d x}=0$ ), which means that transport of cations from the defect to the delamination front according to the Nernst Planck equation (eq. 6) will be limited to pure diffusion.

$J_{i}=D_{i} \cdot\left(\frac{d c}{d x}-\frac{R \cdot T}{z \cdot F} \cdot c_{i} \cdot \frac{d \phi}{d x}\right)$

where $\mathrm{J}$ is the flux, $\mathrm{c}$ the ionic concentration, $\mathrm{D}$ the diffusion coefficient, $\mathrm{R}$ the universal gas constant, $\mathrm{T}$ the absolute temperature, F Faradays constant, $\mathrm{z}$ the charge of the considered specie and $\phi$ the electrical potential created by the ionic species.

However, when the steel is not passivated, the cathodic reaction and the corrosion processes on the steel surface results in a significant electrostatic potential difference 
between the anode and the cathode on corroding systems [51, 52]. The electrochemical potential of the system, $\phi$, is governed by Poisson's equation

$\nabla^{2} \phi=\frac{\sigma}{e}$

where $\sigma$ is the charge density and $e$ the permittivity of the electrolyte solution at the coating-steel interface [53].

From electrochemistry it is known that high ionic strengths eliminate the electrochemical potential [54]. However, in dilute solutions significant electrochemical potential gradient can be established. The electrochemical potential will facilitate the transport of cations from the defect to the delamination front according to the Nernst-Planck flux equation because of migration (i.e. transport of charged species under the action of an electrical field). The preferential transport of cations along the coating-steel interface is further supported by estimations of the resistivity of the coating and the aqueous layer at the coating-steel interface [47].

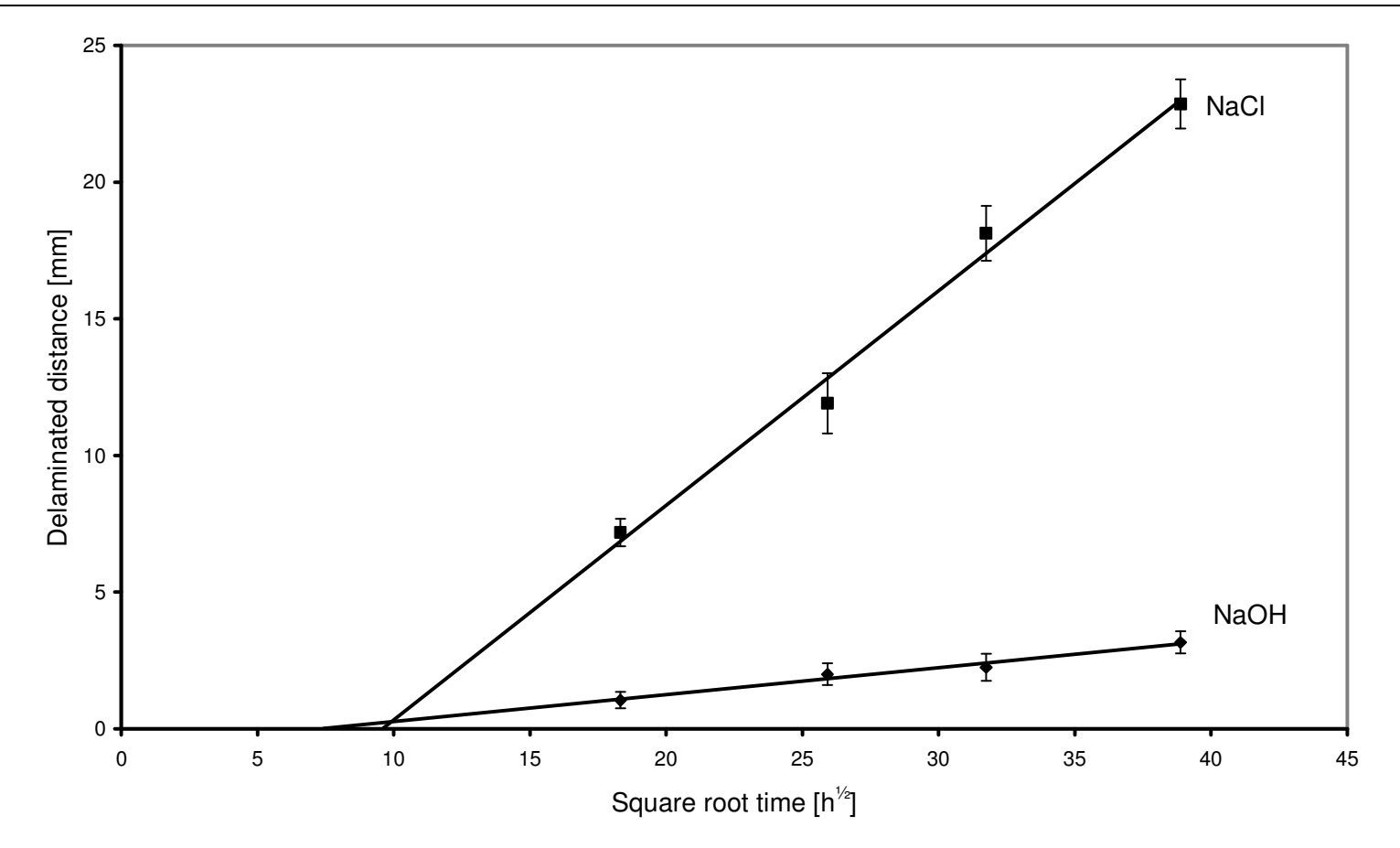

Figure 10: Delamination behaviour of an inert pigmented epoxy coating in 1.0 $\mathrm{M}$ solutions of $\mathrm{NaCl}$ and $\mathrm{NaOH}$ at $25^{\circ} \mathrm{C}$. The vertical lines show the experimental uncertainty.

Indications for the importance of hydroxyl ions in the delamination process are given in Figure 7 where it is obvious that the cathodic delamination process progressed for more than a week although defect was sealed. It may be reasonable to assume that the cathodic reaction underneath the delaminated coating was suppressed by the sealing of the defect because the steel no longer is in direct contact with the bulk solution. If the cathodic reaction was suppressed, the lifetime of the species responsible for the delamination 
exceed the reported half-life of superoxide (1400 s) [55] and/or peroxide species (4 hours) [56] in aqueous solutions. However, it can not be confirmed that the cathodic reaction underneath the coating was suppressed by the blockade of the defect, which means that the reduction of oxygen underneath the coating may have continued to produce harmful species for some time.

The inhibition of the cathodic delamination process was found to coincide with a significant drop in the measured $\mathrm{pH}$ (from around 13 to 11) underneath the coating in the delamination regions. This suggests that at free corrosion potential hydroxyl ions formed at the coating-steel interface by the corrosion processes are the main causative agent for cathodic delamination.

\section{Substrate topography}

The behaviour of anticorrosive coating systems is mainly affected by the condition of the substrate immediately before the coating system is applied [57]. This means that the behaviour of an anticorrosive coating system is to a large extent determined by the presence of contaminants (e.g. salts, dirt, oil and grease) $[58,59]$ and the surface topographic $[35,60]$. The surface topography of the substrate can be controlled and modified, to some extent, by abrasive blasting. Previous studies have shown that roughening of a of metal surface can reduce delamination [14, 28, 61, 62] and improve the adhesion between the coating and the metal [5, 62-64]. However, in many cases adhesion and anticorrosive properties are reported to have a maximum value at a specified roughness (e.g. peak height), which changes with the material, conditions and substrate [62]. The diminished rate of delamination on roughened surfaces has been ascribed to an increase in number of interaction points between the coating and the substrate when the total contact area of the substrate is increased [28, 65]. However, the diffusive nature of cathodic delamination and experimental data [14] suggest that the effect may be caused by an increase of the actual length of the coating-steel interface upon abrasive blasting.

If the rate of cathodic delamination is controlled by diffusion of cations along the coating-steel interface, the delamination rate on substrates with a different degree of roughness should only depend on the tortuosity, $\tau$, and the porosity of the coating-steel interface, $\varepsilon$, because the effective diffusivity, $D_{\mathrm{e}}$, of dissolved species along an interface is given by equation 7[66]. Here it is assumed that the constriction factor is equal to unity.

$D_{e, i}=\frac{\varepsilon}{\tau} D_{i}$

where $\mathrm{D}_{\mathrm{i}}$ is the molecular diffusion coefficient in the coating-steel interface.

The inverse proportionality between the delamination rate and the tortuosity of the coating-steel interface given in Figure 11 shows that cathodic delamination is a diffusion controlled process, where cations must migrate from a defect to the delamination front to neutralize the charge of hydroxyl ions generated by the cathodic reactions. This means 
that the migration of cations as well as the production and migration of hydroxyl ions along the coating-steel interface will determine the rate of cathodic delamination.

It is also clear that the porosity of the coating-steel interface remains unaffected by the size or speed of chilled iron-grit applied for abrasive blasting when residuals from the surface preparation are removed prior to application of the coating because of the inverse proportionality between the delamination rate and the tortuosity.

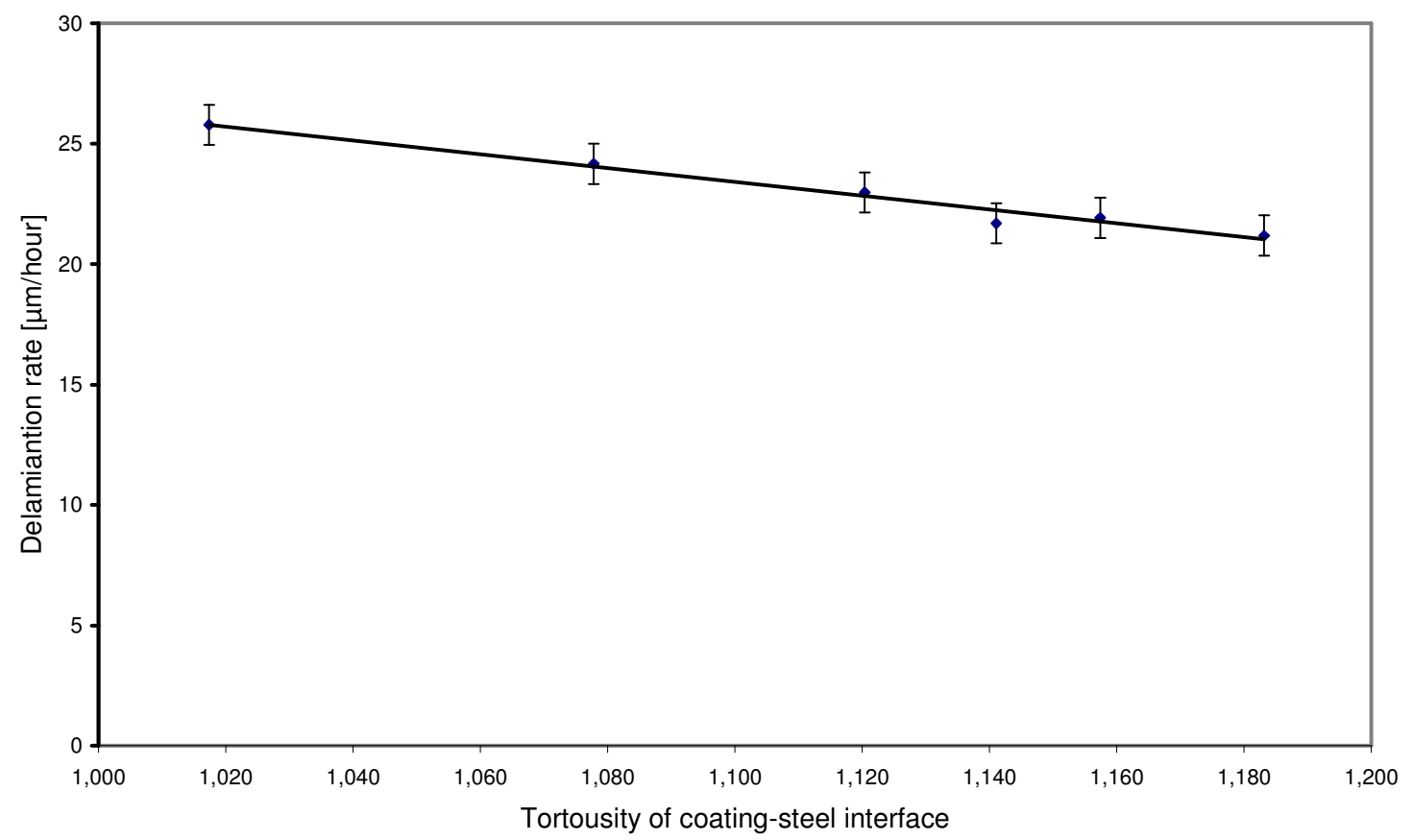

Figure 11: Effect of tortuosity of the coating-steel interface on the delamination rate of a commercial $\mathrm{TiO}_{2}$ pigmented barrier coating. The vertical error bars show the experimental uncertainty.

Although the tortuosity of the coating-steel interface and the total surface area available for interaction between the coating and the steel is controlled by both profile height and the peak density, the standards commonly applied by the coating industry [39] only specify profile height. This means that significant differences in the observed rate of delamination may be encountered on two substrates although the profile heights are identical because the peak densities are different. However, it should be emphasized that neither profile height or peak density provide a proper measure for the tortuosity of the coating-steel interface because these parameters depend on a limited number of isolated events on the surface. This exact problem is illustrated in Figure 12, which shows the delamination behaviour for two selected substrates with similar profile heights and peak densities. The substrate, which has been blasted with finer grit particles has somewhat lower rate of delamination than the corresponding substrate blasted with larger gritparticles although the profile height and peak densities are comparable. This is because the tortuosity describes the actual topography surface more precisely than the profile height and peak density. 


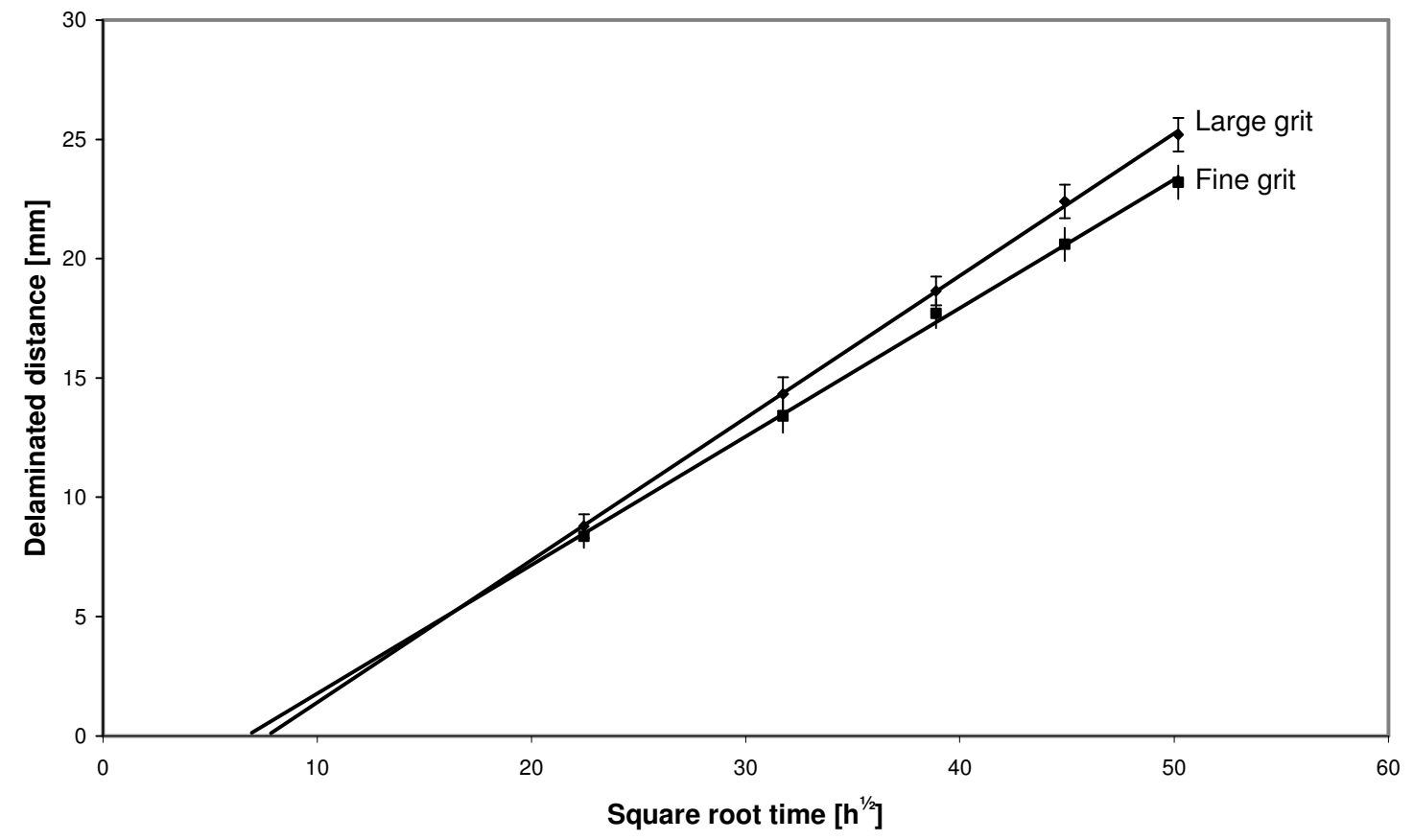

Figure 12: Delamination behaviour for substrate grit blasted with fine grit $\left(R_{z}=41.6, P_{c}=80\right.$ and $\tau=1.183)$ and large size grit $\left(R_{z}=52.6, P_{c}=75\right.$ and $\left.\tau=1.157\right)$. The vertical error bars show the experimental uncertainty.

The experimental data suggests that it would be advantageous to produce substrates with a very high peak density by using small and hard abrasives at a high pressure because this will results in the highest tortuosity. However, the peak density should not be too high because the valleys may become too narrow for complete wetting, which is essential for proper adhesion between the coating and the steel [62]. Incomplete wetting will lead to less coating to steel contact and may leave voids between the coating and the substrate, which will increase the risk of coating failure. This may be particular important for pigmented commercial coatings because pigment particles may get stuck in the valley and prevent complete wetting of the surface by bridging over. This means that greater surface roughness is only advantageous if the liquid coating penetrates completely into all irregularities of the steel surface.

The degree of wetting is described by the angle at which the liquid-vapour interface meets the solid-liquid interface. If the wetting is very favourable, the contact angle will be low, and the liquid coating will spread to cover a larger area of the surface. Although the contact angle of $29^{\circ} \pm 1^{\circ}$ suggest that liquid epoxy resins should wet the surface completely because the surface tension of water $(72.88 \mathrm{dyn} / \mathrm{cm}$ [67]) is higher the surface tension of typical liquid epoxy resins (30-35 dyn/cm [68]) wetting should be considered when formulating coatings. High viscosity of the liquid coating may also result in incomplete wetting of a steel surface if the coating is not allowed sufficient time to spread across the surface and penetrate the irregularities. Hence coatings should be formulated with maximum wetting properties so that substrates with high tortuosity can be used because surfaces with low tortuosity and complete wetting can outperform surfaces with high tortuosity and incomplete wetting. The wettability of a liquid coating 
is determined by several factors such as type of solvent, fineness of pigment grind, type of binder and temperature [62].

\section{Conclusion}

The steel underneath defect coatings is susceptible to corrosion, which eventually will lead to weakening or complete loss of adhesion between the coating and the steel. The cathodic reaction at the delamination front facilitates the transport of cations from the bulk solution to the delamination front, resulting in an alkaline environment which weakens the adhesion between the coating and the steel. The experimental results suggest that hydroxyl ions are the causative agents in the cathodic delamination process. This was proven by the lifetime of the species causing delamination and observed decrease in the $\mathrm{pH}$ in the delaminated regions when the delamination process was stopped.

Although the primary route of the cations required for charge neutralization of the hydroxyl ions is along the coating-steel interface, transport perpendicular to the coating can affect the rate of delamination as illustrated by the observed inverse proportionality between coating thickness and delaminated distance.

The interfacial transport of cations was found to depend solely on the tortuosity of the coating-steel interface. This suggests that the rate determining step for cathodic delamination is along the coating steel interface. The corrosion of the steel and the simultaneous transport of alkali metal ions and hydroxyl ions in opposite directions results in a substantial potential gradient between the anode and the cathode. This suggests that sodium ions are transported from the defect to the delamination front by migration, which is diffusion under the influence of an electrical field.

The tortuosity of the coating-steel interface is determined by the grain size and the speed of the applied abrasive, therefore greater tortuosity can be achieved with finer abrasives. However, although the tortuosity affects the delamination rate significantly, abrasive blasting can not be used to prevent delamination of coating systems. Hence, additional ways of reducing delamination should be investigated.

\section{Acknowledgement}

Financial support by J.C. Hempel's Foundation and the Technical University of Denmark is gratefully acknowledged.

\section{Nomenclature}

$\begin{array}{ll}\mathrm{c}_{\mathrm{i}} & \text { concentration of component } i\left(\mathrm{~mol} / \mathrm{m}^{3}\right) \\ \mathrm{D}_{\mathrm{e}, \mathrm{i}} & \text { effective diffusivity of component } i \text { in the coating-steel interface }\left(\mathrm{m}^{2} / \mathrm{s}\right) \\ \mathrm{D}_{\mathrm{i}} & \text { molecular diffusivity of component } i \text { in the coating-steel interface }\left(\mathrm{m}^{2} / \mathrm{s}\right) \\ e & \text { permittivity }\left(\mathrm{F} \mathrm{m}^{-1}\right) \\ \mathrm{F} & \text { Faradays constant }\left(\mathrm{J} \mathrm{V}^{-1} \mathrm{~mol}^{-1}\right) \\ \mathrm{J}_{\mathrm{i}} & \text { flux of component } i\left(\mathrm{~mole}^{-2} \mathrm{~s}^{-1}\right) \\ \mathrm{k}_{1} & \text { rate constant for direct 4-electron reduction of oxygen to water } \\ \mathrm{k}_{2} & \text { rate constant for 2-electron reduction to peroxide } \\ \mathrm{k}_{3} & \text { rate constant for 2-electron reduction of peroxide to water. } \\ \mathrm{L} & \text { actual surface profile length }(\mu \mathrm{m}) \\ \mathrm{L}_{0} & \text { apparent surface profile length }(\mu \mathrm{m}) \\ \mathrm{L}_{\mathrm{r}} & \text { evaluation length }(\mu \mathrm{m})\end{array}$




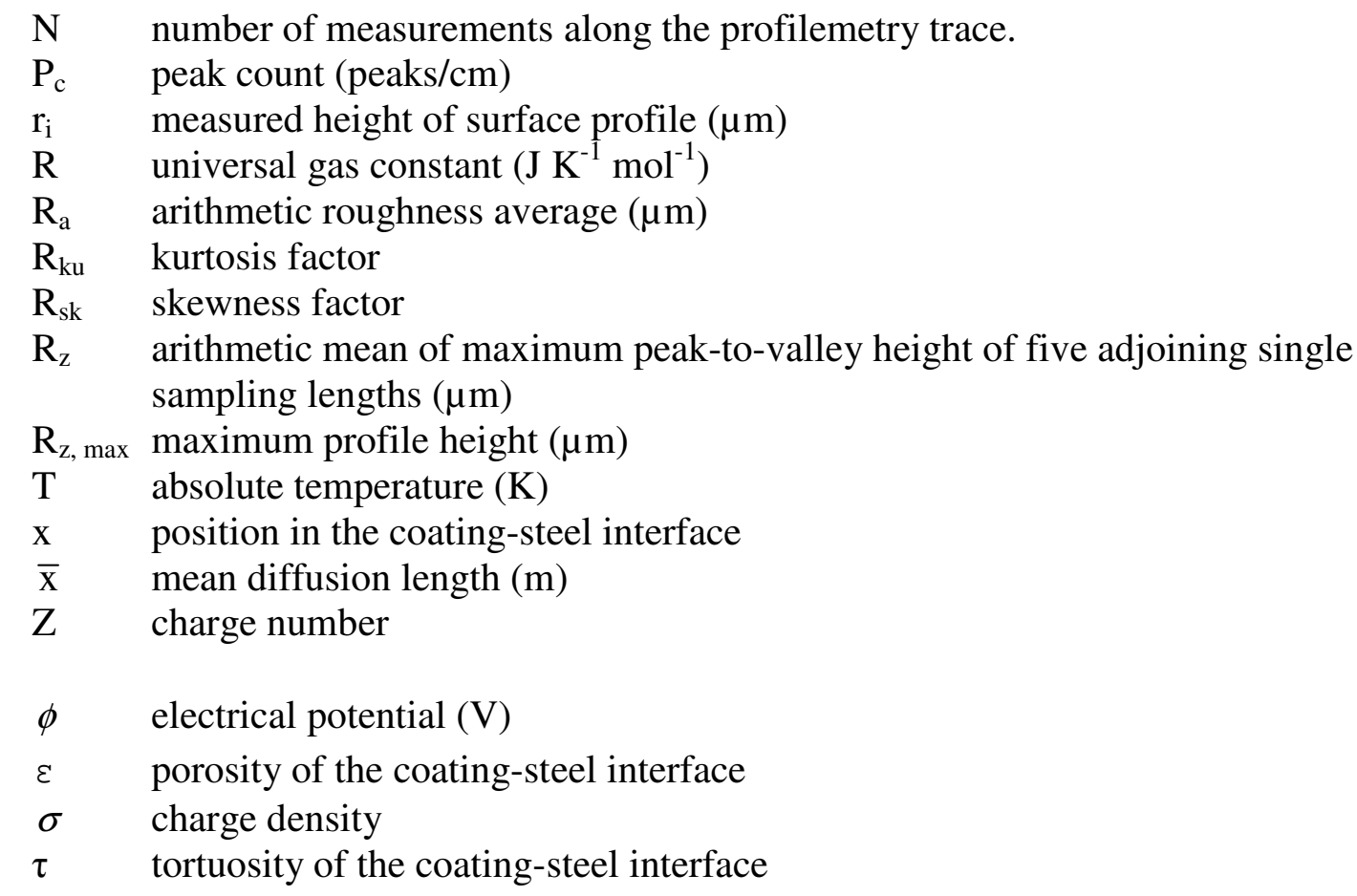

\section{References}

[1] R. A. Dickie, Prog, Org, Coat, 25, (1994), 3.

[2] J. A. Baghdachi, J, Coat, Technol, 69, (1997), 85.

[3] A. C. Rouw, Prog, Org, Coat, 34, (1998), 181.

[4] M. Nakazawa, G. Somorjai, Appl, Surf, Sci, 84, (1994), 309.

[5] P. R. Sere, A. R. Armas, C. I. Elsner, A. R. Di Sarli, Corros, Sci, 38, (1996), 853.

[6] H. Leidheiser, W. Wang, L. Ingetoft, Prog, Org, Coat, 11, (1983), 19.

[7] W. Furbeth, M. Stratmann, Fresenius J, Anal, Chem, 353, (1995), 337.

[8] T. Nguyen, T. B. Hubbard, J. M. Pommersheim, J, Coat, Technol, 68, (1996), 45.

[9] G. Grundmeier, M. Stratmann, Annu, Rev, Mater, Sci, 35, (2005), 571.

[10] A. Leng, H. Streckel, M. Stratmann, Corros, Sci, 41, (1999), 599.

[11] A. Leng, H. Streckel, M. Stratmann, Corros, Sci, 41, (1999), 579.

[12] A. Leng, H. Streckel, M. Stratmann, Corros, Sci, 41, (1999), 547.

[13] J. F. Watts, J. E. Castle, J, Mater, Sci, 18, (1983), 2987.

[14] J. F. Watts, J. E. Castle, J, Mater, Sci, 19, (1984), 2259.

[15] J. J. Ritter, J, Coat, Technol, 54, (1982), 51.

[16] E. L. Koehler, Corrosion, 40, (1984), 5.

[17] E. L. Koehler, J, Electrochem, Soc, 132, (1985), 1005.

[18] R. Feser, M. Stratmann, Materials and Corrosion, 42, (1991), 187.

[19] D. Gervasio, I. Song, J. H. Payer, J, Appl, Electrochem, 28, (1998), 979.

[20] M. Pourbaix, "Atlas of Electrochemical Equilibria in Aqueous Solutions", Pergamon

Press, London

[21] J. M. Atkinson, R. D. Granata, H. Leidheiser, D. G. McBride, J, Res, Dev, 29, (1985), 27. 
[22] S. B. Lyon, L. Philippe, E. Tsuousoglou, Transactions of the Institute of Metal Finishing, 84, (2006), 23.

[23] J. E. O. Mayne, Official Digest, (1952), 127.

[24] V. B. Miskovic-Stankovic, D. M. Drazic, M. J. Teodorovic, Corros, Sci, 37, (1995), 241.

[25] M. Stratmann, R. Feser, A. Leng, Electrochim, Acta, 39, (1993), 1207.

[26] J. I. Skar, U. Steinsmo, Corros, Sci, 35, (1993), 1385.

[27] K. Wapner, M. Stratmann, G. Grundmeier, Electrochim, Acta, 51, (2006), 3303.

[28] X. H. Jin, K. C. Tsay, A. Elbasir, J. D. Scantlebury, Advances in Corrosion

Protection by Organic Coatings, The Electrochemical Society, 87-2, (1987), 37.

[29] J. Parks, H. Leidheiser, Ind, Eng, Chem, Pro, Res, Dev, 25, (1986), 1.

[30] H. Leidheiser, R. D. Granata, J, Res, Dev, 32, (1988), 582.

[31] A. F. Harris, A. Beevers, Int, J, Adhes, Adhes, 19, (1999), 445.

[32] ISO 11124, International Standards Organization, Geneve, 1993

[33] H. J. Roper, R. E. F Weaver , Journal of Protective Coatings \& Linings, June, (2006), 24.

[34] ISO 15711, International Standards Organization, Geneve, 2003

[35] A. W. Momber, W. D. Greverath, Journal of Protective Coatings \& Linings,

February, (2004), 48.

[36]. ISO 4287, International Standards Organization, Geneve, 1997

[37] S. Amada, T. Hirose, Surface and Coatings Technology, 102, (1998), 132.

[38] D. Kjernsmo, K. Kleven and J. Scheie. "Corrosion Protection", Bording A/S, Copenhagen

[39] ISO 8503, International Standards Organization, Geneve, 2003

[40] U. Steinsmo, J. I. Skari, Corros, Sci, 50, (1994), 934.

[41] F. Deflorian, S. Rossi, Electrochim, Acta, 51, (2006), 1736.

[42] H. Leidheiser, W. Wang, J, Coat, Technol, 53, (1981), 77.

[43] D. Bentz, T. Nguyen, J, Coat, Technol, 62, (1990), 57.

[44] J. B. Hubbard, T. Nguyen, D. Bentz, J, Chem, Phys, 94, (1991), 3177.

[45] C. Carneiro, F. Oliveira, J. Nogueira, A. Mendes, J, Coat, Technol, 3, (2006), 159.

[46] Mayne, J. E. O., D. J. Mills, Journal of Oil and Colour Chemists Association, 58, (1975), 155.

[47] O. O. Knudsen and J. I. Skar"Cathodic Disbonding of Epoxy Coatings - Effect of Test Parameters", NACE 2008,

[48] Z. Zecevic, D. Drazic, S. Gojkovic, J, Electroanal, Chem, 265, (1989), 179.

[49] H. Wroblowa, S. Qaderi, J, Electroanal, Chem, 279, (1990), 231.

[50] W. Latimer. "The Oxidation States of the Elements and their Potentials in Aqueous Solutions", Prentice Hall, New York

[51] B. Reddy, J. M. Sykes, Prog, Org, Coat, 52, (2005), 280.

[52] B. Reddy, M. J. Doherty, J. M. Sykes, Electrochim, Acta, 49, (2004), 2965.

[53] S. M. Sharland, Corros, Sci, 27, (1987), 289.

[54] O. Hiroyuki. "Electrochemical Aspects of Ionic Liquds", Wiley, Hoboken

[55] H. S. Wroblowa, J, Electroanal, Chem, 339, (1992), 31.

[56] R. J. Watts, D. D. Finn, L. M. Cutler, J. T. Schmidt, A. L. Teel, J, Contam, Hydrol, 91, (2007), 312.

[57]. ISO 8502, International Standards Organization, Geneve, 1992 
[58] M. Morcillo, Prog, Org, Coat, 36, (1999), 137.

[59] de la Fuente, D., M. Bohm, C. Houyoux, M. Rohwerder, M. Morcillo, Prog, Org, Coat, 58, (2007), 23.

[60] A. W. Momber, S. Koller, H. J. Dittmers, Journal of Protective Coatings \& Linings, November, (2004), 44.

[61] M. Rebhan, M. Rohwerder, M. Stratmann, Materials and Corrosion, 54, (2003), 19.

[62] H. J. Roper, R. E. F Weaver, Journal of Protective Coatings \& Linings, June, (2005), 52.

[63] K. Meine, K. Kloss, T. Schneider, D. Splatmann, Surface and Interface Analysis, 36, (2004), 694.

[64] D. Varacalle, D. Guillen, D. Deason, W. Rhodaberger, E. Sampson, J, Therm, Spray Technol, 15, (2006), 348.

[65] C. Hare, "Good Painting Practice. Steel Structures Painting Manual", Steel Structues Painting Council, Pittsburg

[66] H. S. Fogler, "Elements of Chemical Recation Engineering", Prentice Hall, New Jersey

[67] D. R. Lide, "CRC Handbook of Chemistry and Physics", Taylor and Francis, Boca Raton

[68] C. Cheng, H. Lin, IEEE Trans, Adv, Pack, 31, (2008), 100. 